\title{
Designing of Hot Strip Rolling Mill Control System
}

\section{Yajun Wu}

School of Application Technology, University of Science and Technology Liaoning, Anshan, China

Email: shyuhaii@163.com

Received 7 July 2016; accepted 2 August 2016; published 5 August 2016

Copyright (C) 2016 by author and Scientific Research Publishing Inc.

This work is licensed under the Creative Commons Attribution International License (CC BY).

http://creativecommons.org/licenses/by/4.0/

cc) (i)

Open Access

\section{Abstract}

Aimed at the complex demand of hot strip rolling mill in practicing, the configuration of the coiler and the technological process is analyzed. The arithmetic of coiling tension and the control process is introduced. The frame of the tension adjusting system is given. The coiler control system hardware is designed. The system is designed scientifically with steady control and meets demand of the market.

\section{Keywords}

\section{Hot Strip Rolling, Coiler, Tension Control}

\section{Introduction}

In most modem hot rolling procedure, the strips are coiled up in continuity. Coiling is the last key production step in hot rolling procedure, which is done by the coilers. The coilers are indispensable important equipment in hot strip rolling line. Their main task is to coil the strip out of the finishing mill, and then transport to the next working procedure. The core part of coiling control system is the tension control. The control effect of coiling tension is directly related to the production and quality of hot rolled strip steel, therefore tension must be maintained constant in the process of coiling.

\section{The Process of Coiling System}

Coiling area including the last finishing mill export to the end of the transport chain, the main equipment are hot run out table, the side guide, pinch roll, wrapper roll, mandrel, discharging coil car, transport, etc., as shown in Figure 1 [1].

In actual controlling process, there are two main types of coiler control modes, speed control and tension con- 


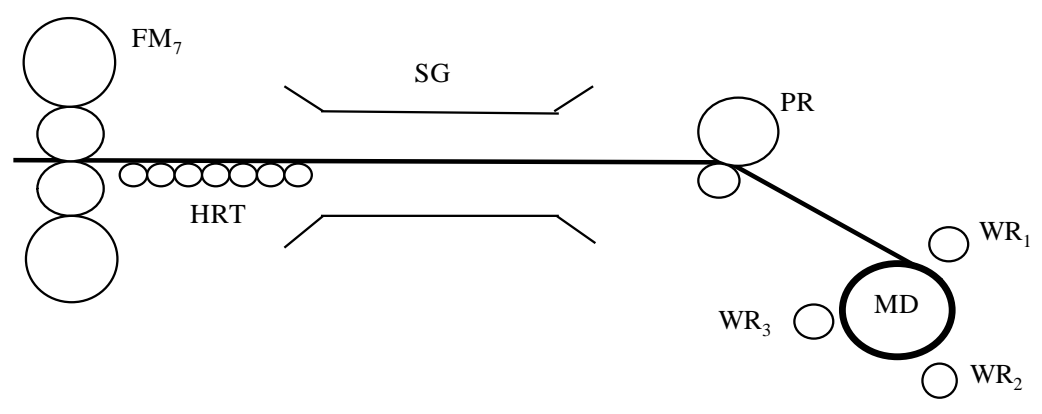

Figure 1. Diagram of hot mill coiler equipment.

trol, both transformed under certain conditions, as shown in Figure 2. The former and later stages are speed control. The first stage, when the strip head left out of the last finishing mill and signal is 1 , the speeds of the hot run out table and the pinch roll are greater than the speed of the strip out of the last finishing mill, the speed of mandrel is greater than the speed of pinch roll. Therefore the speed given of the hot run out table, pinch roll and mandrel is the speed of the last finishing mill plus a certain lead rate, the lead rate is given in man-machine interface through the console. The second stage, when the strip tail through the last finishing mill and signal from 1 to 0 , the speed of mandrel equals the speed of strip which switch from tension control to speed control, the speed of the hot run out table, pinch roll and wrapper roll is less than the speed of strip, the value of lag rate is given in man-machine interface by the console.

In the process of the whole tension control and speed control switch, when the reel tension building, the speed given of the mandrel plus an additional speed $\Delta \mathrm{n}$, make speed values reach saturation, to switch to the tension control. When the tension control switch to the speed control, to cancel the additional speed $\Delta \mathrm{n}$.

In the working process of the coiler, from the strip head into the mandrel set up tension to the strip tail left the last finishing mill, the coiler entered the stage of tension control. Strip tensions are mainly provided between mandrel and pinch roll, between pinch roll and finishing mill. In order to make full use of the motor torque, the tension control system adopts the maximum torque method [2]. The basic control process is: when the mandrel works under the basic speed, motor is in full magnetic state. $\Phi=\Phi$ Max $=$ Constant, at this time as long as guarantee the I/D constant. when the mandrel works above the basic speed, control motor potential $\mathrm{E}$ constant by excitation regulator, $\mathrm{E}=\mathrm{Ce} \Phi \mathrm{n}=$ Const, $\Phi$ is inversely proportional to the $\mathrm{n}$. Because $\mathrm{n}=60 \mathrm{iv} / \pi \mathrm{D}, \mathrm{E}=$ $\mathrm{Ce} \Phi 60 \mathrm{iv} / \pi \mathrm{D}$. The velocity is constant when rolling stable, then the $\Phi / \mathrm{D}$ is constant, according to $\mathrm{T}=2 \mathrm{iCm} \Phi \mathrm{I} / \mathrm{D}$, as long as adjust current I constant, it can realize the strip steel tension constant.

It is automatic from the speed control switch to the tension control under the switch logic control. The speed given of coiler has been advancing the speed of the last finishing mill before the last finishing mill thrown strip. It automatically switch to the tension control after tension establishing between the last finishing mill and mandrel. Tension given is determined by tension torque, friction torque, bending torque and inertia torque [3].

\section{Coiling Tension Control Model}

\subsection{Tension Torque}

$$
\mathrm{T}_{\mathrm{F}}=\mathrm{Ut} \times \mathrm{W} \times \mathrm{h} \times(\mathrm{D} / 2) \times \gamma
$$

where, $U$ t is unit tension $(\mathrm{kg} / \mathrm{mm}), \mathrm{W}$ is strip width (m), h is strip thickness $(\mathrm{m})$, D is soil diameter $(\mathrm{m}), \gamma$ is gear reduction ratio.

Winding tension value depends on the coiler working status and product specifications. The improper tension value will directly affect the quality of the products. Visible, tension value should be carefully choice. According to the different thickness of steel in combination with the actual situation, it is given a complete set of the parameters of the coiling unit tension, as shown in Table 1. In practice, set the strip steel tension in accordance with the data in Table 1 . The operator can also manually adjust according to the actual situation the coiling tension.

\subsection{Bending Torque}

$$
\mathrm{T}_{\mathrm{B}}=\mathrm{W} \times \mathrm{h}^{2} \times \sigma / 4
$$




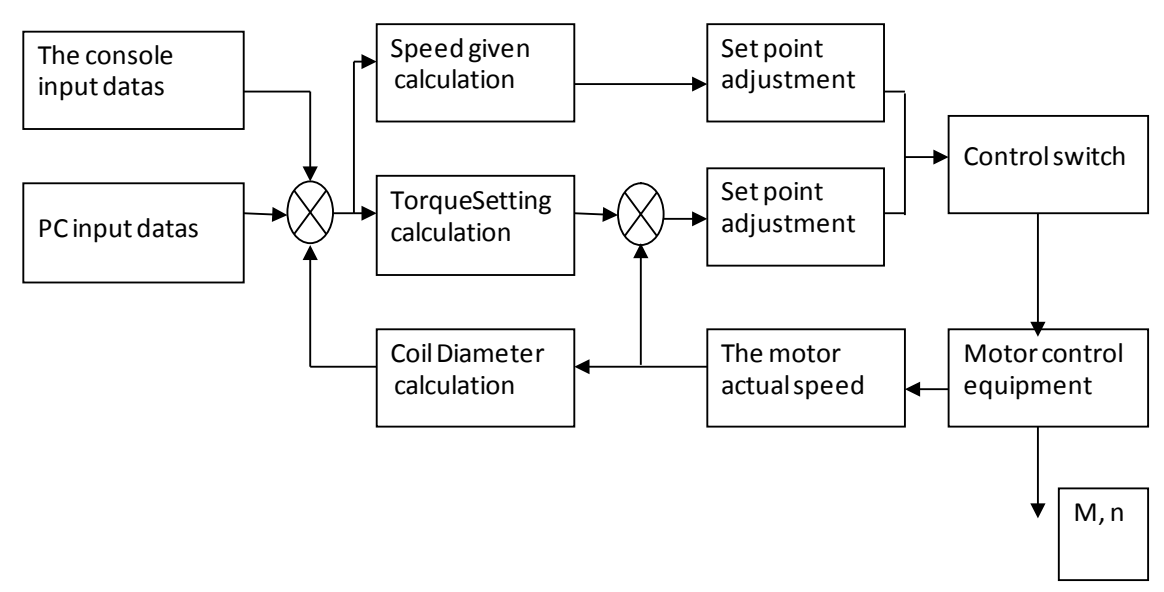

Figure 2. Diagram of coiler control process.

Table 1. The tension value of Ut of hot roll strip mill.

\begin{tabular}{ccccc}
\hline Strip width (mm) & $\mathrm{h} \leq 2.5$ & $2.5<\mathrm{h} \leq 3.0$ & $3.0<\mathrm{h} \leq 5.0$ & $5.0<\mathrm{h}$ \\
\hline Unit tension (MPa) & 16.02 & 14.56 & 12.41 & 11.17 \\
\hline
\end{tabular}

where $\sigma$ is yield stress. Yield torque which strip bending deformation needed occupies a larger proportion in the total output torque. Bending torque changes according to the material properties and its size, so it is a very important to calculate the torque.

\subsection{Inertia Torque}

$$
\begin{aligned}
& \mathrm{T}_{\mathrm{i}}=\left(\mathrm{GD}^{2} / 375\right) \times(\mathrm{dn} / \mathrm{dt})=\left(\mathrm{GD}^{2} / 375\right) \div(\pi \times \mathrm{D}) \times(\mathrm{dv} / \mathrm{dt}) \\
& \mathrm{GD}^{2}=\mathrm{GD}_{0}^{2}+(\pi / 8) \times \rho \times \mathrm{W} \times\left(\mathrm{D}^{4}-\mathrm{D}_{0}^{4}\right)
\end{aligned}
$$

where $\mathrm{GD}^{2}$ is the sum of all the rotational inertia of the motor shaft. GD0 ${ }^{2}$ is the rotational inertia of the fixed part (including the motor and the drum). $\rho$ is the density of steel strip $\left(7.8 \times 10^{3} \mathrm{Kg} / \mathrm{m}^{3}\right)$.

The speed of mandrel changes with coiling. Deceleration torque calculation shall be according to the moment of inertia of mandrel to keep the strip tension control accurate .The mandrel rotational inertia also changes over winding diameter.

\subsection{Coiling Diameter Calculation}

$$
\mathrm{D}=\mathrm{V}_{\mathrm{L}} /(\pi \times \mathrm{n})
$$

where $\mathrm{V}_{\mathrm{L}}$ is strip velocity (mpm), $\mathrm{n}$ is mandrel speed (rpm), $\mathrm{D}$ is coil diameter (m).

Coiling diameter calculation adopts speed ratio method, which has the advantage of no accumulated error and does not have to consider a coil volume tightness. But it could be sliding between strip and pinch roll, which is the main factor that affected the accuracy of coiling diameter calculation.

Coiler tension control principle diagram is shown in Figure 3.

\section{Designing of Control System}

Control system adopts three layers of network structure, as shown in Figure 4. PCs use Proficy CIMPLICITY configuration software to configurate with PAC system variables. CIMPLICITY HMI support distributed structure of Internet, it can realize computer control. The system selects the GE PAC Systems RX7i series PLC, which have high performance CPU Pentium III processor; 10/100 M adaptive high-speed Ethernet card to convenient connection communication. It adopts Proficy Machine Edition programming software, which unified programming environment and communal development tool is convenient for users to share data and network 


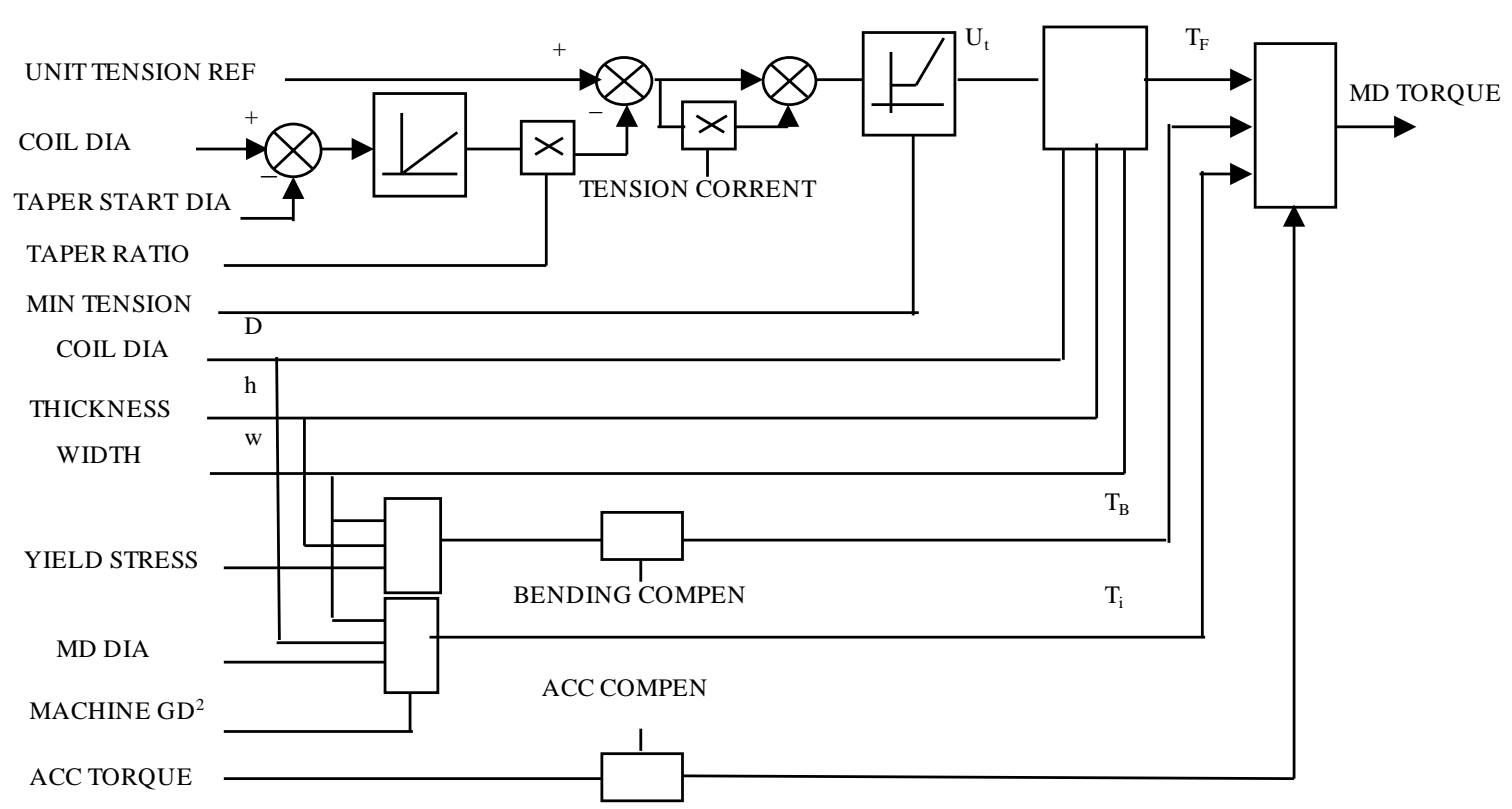

Figure 3. Tension adjust system schematic diagram.

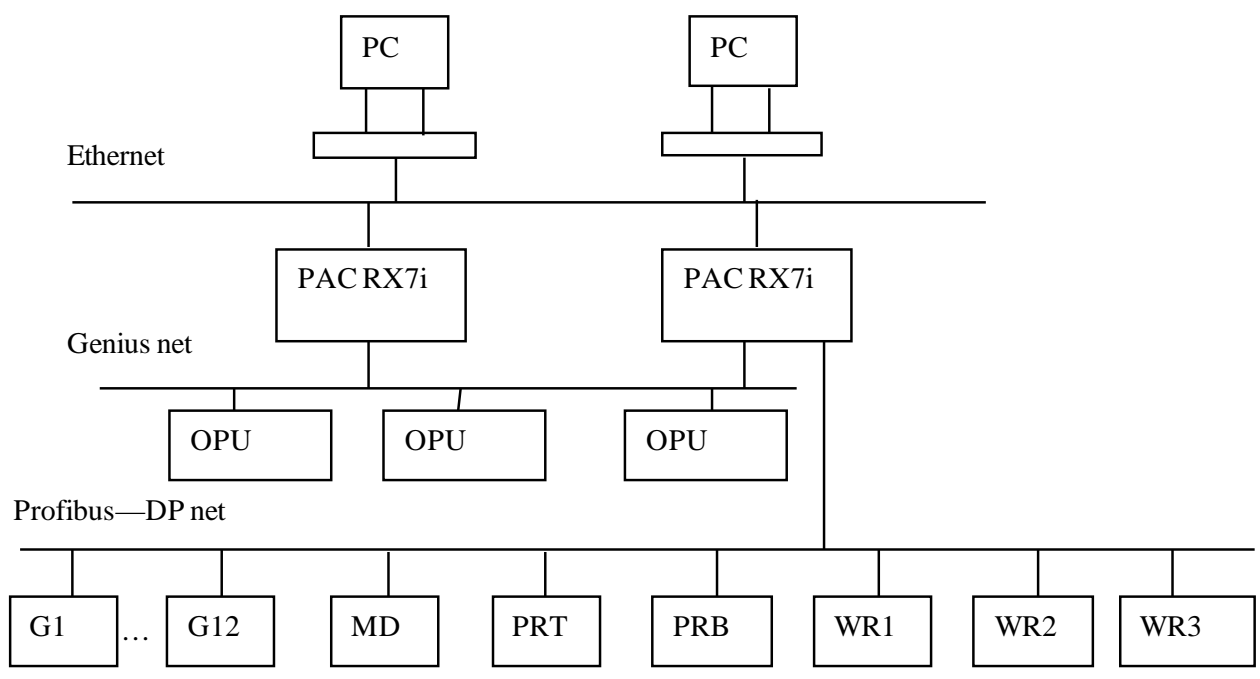

\section{Figure 4. Hardware of the system.}

operation. Manual operation between work station and PLC are realized through the Genius network. It exchange data of process control and control commands to based automatic control system through Profibus-DP. The system choose S120 frequency conversion device [4] and use SCOUT software to set the synchronous motor drive unit, control unit and the parameters of the encoder.

PLC main functions: the first PLC completed the command/tension control, including: tension control; speed control of mandrel and run out table; tracking the strip head and tail; monitoring equipment of coiling area. The second PLC finished coiler control, including: coiler cooling water control; pinch roll ancillary equipment (pressure roller, valve, etc.) control; mandrel, pinch roll and wrapper roll electrical logic control; wrapper roll gap control, pressure control, leapfrog control; pinch roll gap control, pressure control; The entry side guide control; drum swell-shrink control; discharge volume control.

\section{Experiment Results}

Figure 5 is process control curve which coiler record in the process of actual production .It can be seen from the 


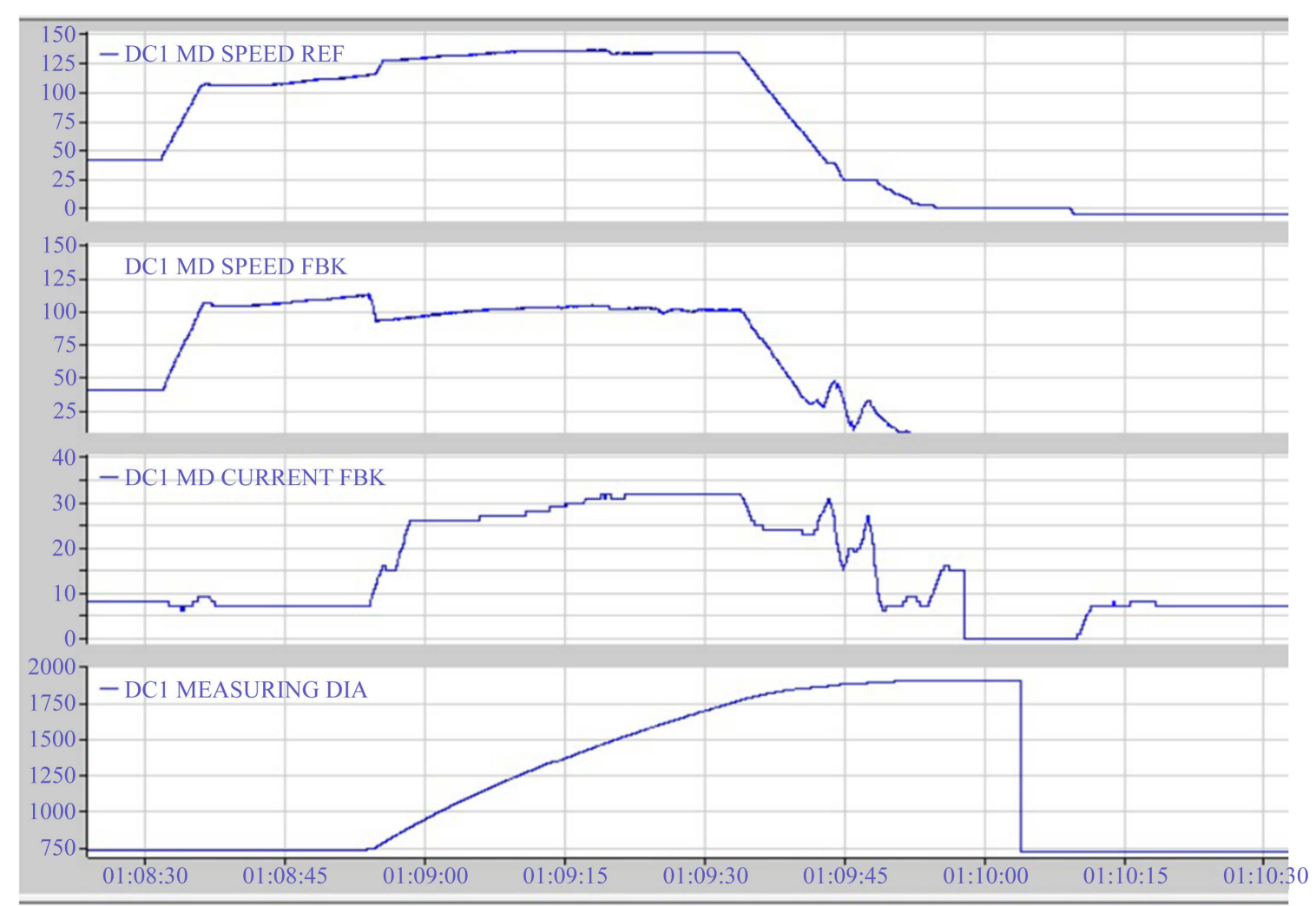

Figure 5. Some process data of coiling.

chart that DC MD SPEED REF is greater than DC MD SPEED FBK in the coiling tension control stage. As the growth of the roll diameter, the actual torque of mandrel can automatically adjust to maintain the tension constant. After FM7 cast steel, strip steel coiling control method switch for speed control and operating normally.

\section{Conclusion}

Constant tension control is an important factor of hot coiling quality control. The most important standard of coil quality is control accuracy which can realize automatic constant tension. This article introduces that the design of the control system of strip coiling has universal significance. Due to its system to choose reasonable core equipment, combining with advanced control algorithm, efficient and stable data network, is good to achieve the constant coiling tension control in the process of rolling. In practice, it achieved good economic benefits.

\section{References}

[1] Cui, J.J. (2006) Hot Rolling Coiler Simulation System Research. Journal of System Simulation, 18, 636-642. (In Chinese)

[2] Li, F.Y. (2009) Automatic Control and Application of Hot Rolled Plate Coiling Machine. Mechanical and Electrical Engineering, 38, 36-38. (In Chinese)

[3] Huang, Y. (2008) Designing of Hot Strip Rolling Mill Control System Based on PLC. Electrical Transmission, 38, 5659. (In Chinese)

[4] Yu, C.Z. (2009) Hot Rolling Coiler Tension Control. Metallurgical Automation, S2, 474-478. (In Chinese) 


\section{Submit or recommend next manuscript to SCIRP and we will provide best service for you:}

Accepting pre-submission inquiries through Email, Facebook, LinkedIn, Twitter, etc.

A wide selection of journals (inclusive of 9 subjects, more than 200 journals)

Providing 24-hour high-quality service

User-friendly online submission system

Fair and swift peer-review system

Efficient typesetting and proofreading procedure

Display of the result of downloads and visits, as well as the number of cited articles

Maximum dissemination of your research work

Submit your manuscript at: http://papersubmission.scirp.org/ 